\title{
O PROBLEMA LÓGICO DO MAL
}

\author{
o argumento de Mackie e a resposta do livre-arbítrio
}

THE LOGICAL PROBLEM OF EVIL

Mackie's argument and the answer of free will

Gabriel Reis de Oliveira ${ }^{1}$

(reisgabri@gmail.com)

\begin{abstract}
RESUMO
Este artigo tem por objetivo analisar criticamente a versão lógica do problema do mal. Segundo o problema lógico do mal, a existência do deus teísta é logicamente incompatível com a existência do mal. Atualmente, um dos mais importantes defensores do problema lógico do mal é J. L. Mackie, e é em sua formulação que nos concentramos. Apresentamos duas respostas expostas e examinadas pelo próprio Mackie; em seguida, damos atenção à defesa do livre-arbítrio de Alvin Plantinga, que visa a superar as críticas anteriores de Mackie a uma versão dessa defesa que apela ao livre-arbítrio com o objetivo de compatibilizar logicamente a existência de Deus com o mal. Concluímos que a defesa de Plantinga falha em bloquear a conclusão do argumento de Mackie e apresentamos, em seguida, uma resposta econômica que neutraliza com sucesso o problema lógico. Por fim, concluímos que o mal não levanta um problema lógico à existência de Deus.
\end{abstract}

Palavras-chave: Deus. Lógica. Mal.

\begin{abstract}
This article aims to critically analyze the logical version of the problem of evil. According to the logical problem of evil, the existence of the theistic god is logically incompatible with the existence of evil. One of the most important proponents of the logical problem of evil today is J. L. Mackie, and it is in his formulation that we concentrate. We present two answers exposed and examined by Mackie himself; we then turn to Alvin Plantinga's defense of free will to overcome Mackie's previous criticisms of a version of such defense that calls for free will in order to logically reconcile God's existence with evil. We conclude that Plantinga's defense fails to block the conclusion of Mackie's argument, and we then present an economic answer that successfully neutralizes the logical problem. Finally, we conclude that evil does not pose a logical problem to the existence of God.
\end{abstract}

Keywords: God. Logic. Evil.

\footnotetext{
${ }^{1}$ Mestrando em Lógica e Metafísica pela Universidade Federal do Rio de Janeiro (UFRJ).

CV Lattes: http://lattes.cnpq.br/4798343424731799.

ORCID: https://orcid.org/0000-0002-1949-0148.
} 


\section{INTRODUÇÃO}

O problema do mal consiste na questão de se saber como compatibilizar a existência do deus teísta, isto é, de um ser onipotente, onisciente e sumamente bom, com a existência do mal no mundo. Contemporaneamente, o problema do mal é dividido entre o problema lógico e o problema evidencial do mal. Segundo o problema lógico, a existência de Deus é logicamente incompatível com a existência do mal; segundo o problema evidencial, mesmo que a existência de Deus seja logicamente compatível com a existência do mal, ela não deixa de ser problemática, parecendo oferecer um indício contra a existência de Deus. Meu objetivo neste trabalho é analisar criticamente o problema do mal em sua versão lógica.

Segundo as pesquisas de Michael W. Hickson (2013), o primeiro escrito verificável ${ }^{2}$ que buscou apontar a inconsistência lógica da existência de Deus com a existência do mal encontra-se na obra anônima intitulada Jordanus Brunus Redivivus (1760-1770). Atualmente, um dos mais importantes defensores do problema lógico do mal é J. L. Mackie (1955), e é em sua formulação que me concentrarei.

Antes de começar, no entanto, é importante distinguir, para nossos fins, o que é conhecido na literatura por defesa e aquilo que ficou conhecido por teodiceia. Apesar de haver alguma controvérsia sobre como caracterizar essas noções, assumirei que uma defesa é uma resposta ao argumento antiteísta gerado pelo problema lógico do mal. Nesse sentido, uma defesa tem por objetivo mostrar em que medida a existência de Deus pode ser compatível com a existência do mal, o que significa que tal defesa tem por objetivo oferecer um exemplo de um bem maior que poderia ser a razão para Deus permitir o mal. Contudo, essa explicação não precisa ser verdadeira, apenas possível, mostrando sua compatibilidade lógica. Já uma teodiceia é uma tentativa de explicar e especificar a verdadeira razão por que Deus permite o mal - apontando o bem maior que realmente justificaria a Deus permitir o mal. Assim, uma teodiceia é algo mais exigente do que uma mera defesa, já vez que naquela se pretende justificar a existência do mal, dada a existência de Deus, oferecendo-se a verdadeira razão de Deus para permitir o mal.

Outra distinção relevante é a feita entre mal moral e mal natural. John Hick oferece uma descrição muito concisa dessa distinção quando escreve: “O mal moral é o que nós seres humanos originamos: pensamentos e atos cruéis, injustos, viciosos e penetrantes." (HICK,

\footnotetext{
${ }^{2}$ De acordo com Hickson (2013), em sua pesquisa histórica sobre o problema do mal, o dilema comumente atribuído a Epicuro carece de fontes constatativas para sua autoria. Além disso, segundo as pesquisas do autor, na Antiguidade e na Idade Média os filósofos não viam o mal como argumento contra a existência de Deus.
} 
2010, p. 12) O mal moral é o tipo de mal pelo qual um agente é moralmente responsável, incluindo tanto ações (como mentir, estuprar, assassinar etc.) quanto traços de caráter (como malícia, ganância, inveja etc.). “O mal natural é o mal que se origina independentemente das ações humanas: na doença [...], terremotos, tempestades, secas, tornados, etc.” (HICK, loc. cit.) O mal natural inclui aqueles eventos pelos quais os agentes morais não são responsáveis.

Feitas essas distinções, podemos agora passar a analisar o problema do mal em sua versão lógica. Em particular, no decorrer deste artigo apresentarei a formulação do ateólogo ${ }^{3}$ J. L. Mackie (1955) do problema do mal e contrapô-lo com possíveis respostas teístas; apresentarei também uma refutação a Mackie através da defesa do livre-arbítrio do teísta Alvin Plantinga (1974a e 1974b) e de seus críticos, finalizando com uma resposta econômica que neutraliza o argumento de Mackie.

\section{O PROBLEMA LÓGICO DO MAL}

\section{1 $O$ argumento do mal de J. L. Mackie}

O argumento de Mackie (1955) é atualmente a defesa mais conhecida de que o mal implica a impossibilidade lógica da existência de Deus. Em seu artigo, ele pretende mostrar não que "as crenças religiosas carecem de uma base racional, mas sim que elas são decisivamente irracionais, que as várias partes da doutrina teológica fundamental são inconsistentes entre si" (MACKIE, 1955, p. 200). Assim, ele inicia seu artigo apresentando as seguintes premissas:

(1) Deus é onipotente, onisciente e sumamente bom;

(2) O mal existe.

Mackie não inclui explicitamente a onisciência em seu argumento. Ora, sem a onisciência, seria possível que Deus desconhecesse a existência do mal no mundo; desse modo, para construirmos o argumento, assumirei que Deus é onisciente, isto é, que Deus conhece todas as coisas. Obviamente, não há inconsistência ou contradição entre (1) e (2), uma vez que, para que haja um conjunto de proposições contraditórias, é necessário que uma seja a rejeição ou negação de outra. Mackie (1955, p. 200) reconhece que "a contradição não surge imediatamente" de ambas as premissas, mas que para se demonstrar a

3 “Áteólogo" é o termo que Plantinga usa para se referir aos antiteístas defensores do problema do mal. 
inconsistência são necessárias algumas premissas adicionais em relação aos termos utilizados, nomeadamente "bem", "mal" e "onipotente". O bem é o oposto do mal, de tal forma que:

(3) "Uma coisa boa, na medida em que pode [e sabe], sempre elimina o mal." (1955, p. 201)

Além disso,

(4) "Não há limites ao que uma coisa onipotente pode fazer."

De (3) e (4), segue-se que:

(5) "Uma coisa boa[, onisciente] e onipotente elimina completamente o mal."

Portanto, de (2) e (5) segue-se que:

(6) “'Uma coisa boa[, onisciente] e onipotente existe' e 'o mal existe' são proposições incompatíveis."

Logo, dada a existência do mal,

(7) "Não há uma coisa boa, onisciente e onipotente" (de 2 e 6).

Meu próximo objetivo é examinar duas respostas teístas a esse argumento, ambas expostas e examinadas pelo próprio Mackie.

\subsection{Duas possíveis defesas teístas e as críticas de Mackie}

Ao analisar possíveis defesas que o teísta poderia dar ao problema lógico do mal por ele formulado, Mackie (1955, p. 206) diz que uma das alternativas teístas de resposta é afirmar que o "universo é melhor contendo algum mal do que ele seria se não houvesse mal". Ele escreve:

$\mathrm{Na}$ apresentação do problema do mal relativamente descomprometida de Hume, os males que ele ressalta são a dor e a doença, e aqueles que se opõem a ele argumentam que a existência da dor e da doença torna possível a existência da piedade, da benevolência, do heroísmo e da luta dos médicos e dos reformadores progressivamente bem-sucedida para superar esses males. (MACKIE, 1955, p. 206, tradução nossa) ${ }^{4}$

Para esclarecer essa resposta teísta, Mackie distingue o que ele chama de bem e mal de primeira ordem e de segunda ordem. Dor e miséria são exemplos de males de primeira ordem; por sua vez, prazer e felicidade são bens de primeira ordem. Normalmente, aqueles que

\footnotetext{
4 "In Hume's rather half-hearted presentation of the problem of evil, the evils that he stresses are pain and disease, and those who reply to him argue that the existence of pain and disease makes possible the existence of sympathy, benevolence, heroism, and the gradually successful struggle of doctors and reformers to overcome these evils."
} 
tentam justificar a existência do mal de primeira ordem afirmam que existe um bem de segunda ordem que, de alguma forma, emerge de uma situação complexa na qual o mal é um componente logicamente necessário. Isso significa que não poderia haver um bem de segunda ordem sem um mal de primeira ordem: a "existência da dor e da doença torna possível a existência da piedade, da benevolência, do heroísmo" (MACKIE, 1955, p. 206). Por exemplo, a coragem é um bem de segunda ordem, porque ninguém jamais poderia desenvolver esse traço de caráter se não houvesse dores e males de primeira ordem que causassem medo. É plausível assumir que esse bem de segunda ordem seja mais importante do que o mal de primeira ordem que o possibilita, dessa forma superando-o.

Mackie faz uma observação crítica que ele acredita ser fatal, afirmando que, assim como o bem de primeira ordem tem uma contrapartida no mal de primeira ordem, o mesmo deve valer para o de segunda ordem. O mal de segunda ordem inclui

[...] a malevolência, a crueldade, a insensibilidade, a covardia e estados nos quais o bem [de primeira ordem] diminui e o mal [de segunda ordem] cresce. E, assim como o bem [de segunda ordem] é tido como um tipo importante de bem, o tipo que Deus busca promover, então, por analogia, o mal [de segunda ordem] será um tipo importante de mal, o tipo que Deus, se fosse sumamente bom[, onisciente] e onipotente, eliminaria. (MACKIE, 1955, p. 207-208, tradução nossa) ${ }^{5}$

Mas, como a evidência confirma, existem males de segunda ordem. Se o teísta persistir com essa solução de níveis de males e bens, seria agora forçado a postular bens de terceira ordem para explicar a ocorrência dos males de segunda ordem, e teríamos também males de terceira ordem em contraste. Isto é, para cada bem superior postulado para explicar males de ordem inferior há, correspondentemente, males do mesmo nível, o que por sua vez levaria a termos de apelar a um bem de ordem superior para os explicar e assim até o infinito. Desse modo, o argumento do mal de Mackie pode ser reformulado com base nos males da ordem correspondente aos bens de ordem superior que servem para explicar a ocorrência dos males de ordem inferior - ou seja, essa defesa ao problema lógico do mal não é satisfatória.

Outra defesa teísta ao problema lógico do mal de Mackie é baseada na ideia de que o mal existente resulta do livre-arbítrio das criaturas humanas. Fazendo uso das distinções anteriores entre diferentes ordens de bem e mal, Mackie afirma que a noção de que o mal

\footnotetext{
5 "[...] malevolence, cruelty, callousness, cowardice, and states in which good (1) is decreasing and evil (1) increasing. And just as good (2) is held to be the important kind of good, the kind that God is concerned to promote, so evil (2) will, by analogy, be the important kind of evil, the kind which God, if he were wholly good and omnipotent, would eliminate."
} 
resulta da liberdade humana não tem o problema de incorrer num regresso ao infinito, pois o mal de segunda ordem "não é justificado, mas é antes atribuído aos seres humanos de tal forma que Deus não pode ser responsável por ele" (MACKIE, 1955, p. 208). Apesar disso, o ataque de Mackie à resposta do livre-arbítrio concentra-se inicialmente nessa noção de diferentes níveis de bem e de mal. Ele alega que, em essência, a resposta do livre-arbítrio repousa na crença de que a liberdade, mesmo que envolva cometer certos males, isto é, mesmo que possibilite a existência de males de primeira e segunda ordem, é um bem de terceira ordem, e os bens que ela produz são de maior valor do que quaisquer bens de segunda ordem produzidos de uma maneira totalmente determinada. Ou seja, o livre-arbítrio das criaturas, além de ser um bem de terceira ordem, é condição de possibilidade tanto dos males de primeira e segunda ordem quanto dos bens valiosos de primeira e segunda ordem.

Desse modo, argumenta-se que os homens foram dotados por Deus de liberdade, de tal modo que o responsável pelos males são as criaturas, e não Deus. Além disso, é melhor um mundo com criaturas livres que tenham a possibilidade de fazer o mal do que criaturas totalmente determinadas que sempre façam o bem. Assim, a existência do mal, em certo sentido, dá-se em razão de um bem maior, nomeadamente, a liberdade da vontade das criaturas. Considerando-se todas as outras possibilidades, é melhor que os homens tenham livre-arbítrio e por vezes errem em suas ações no uso de sua valiosa liberdade do que façam sempre o bem, mas sem liberdade.

Mackie responde a essa defesa do livre-arbítrio apontando que há mundos possíveis onde todas as criaturas agem livremente e fazem o bem em todas as circunstâncias. Ou seja, os males de segunda ordem não se seguem necessária e logicamente da liberdade, pois, "se Deus fez os homens tais que em suas livres escolhas algumas vezes prefiram o bem e algumas vezes o mal, por que ele não poderia ter feito os homens tais que eles sempre escolhessem livremente o bem?” (MACKIE, 1955, p. 209). Não há nada logicamente contraditório em Deus ter criado um mundo onde os homens escolhem livremente e sempre o bem, seja qual for a situação. Portanto, Deus não estaria submetido ao dilema de criar ou robôs determinados, ou seres livres no quais os males estariam necessariamente acompanhados de sua liberdade. Deus teria a "[...] possibilidade, obviamente melhor, de fazer seres que agissem livremente, mas sempre corretamente" (MACKIE, loc. cit.). É logicamente possível que Deus crie um mundo sem mal preservando a valiosa liberdade humana. 
Assumindo que não há contradição em um mundo onde criaturas livres sempre escolhem o bem em todas as circunstâncias possíveis, poderíamos então reformular o argumento do mal de Mackie da seguinte forma:

(8) Há mundos possíveis em que há criaturas livres que sempre escolhem o bem em todas as circunstâncias;

(9) Uma coisa boa, onisciente e onipotente pode e quer criar um mundo que contenha criaturas significativamente livres que sempre escolham o bem em todas as circunstâncias possíveis (de 3 e 4).

Deve-se levar em conta que:

(10) O mundo atual contém criaturas livres que escolhem o mal (de 2).

Podemos concluir, então, que

(11) Não há uma coisa boa, onisciente e onipotente (de 9 e 10).

Mackie levanta mais uma objeção à defesa do livre-arbítrio: ele diz que alguns podem responder que sua objeção é absurda porque a realização de algumas escolhas erradas é logicamente necessária para a liberdade. No entanto, afirma Mackie, eles estão pensando na liberdade como completa aleatoriedade ou indeterminação, incluindo aleatoriedade em relação às alternativas boas e más. Mackie diz que isso significa que as escolhas dos homens podem ser livres, nesse sentido, somente se não forem determinadas por seu caráter; porém, se as escolhas são aleatórias, então não são genuinamente escolhas livres. Além disso, se a liberdade se baseasse na mera aleatoriedade, não poderia ser o bem mais importante, e assim não valeria a pena possuí-la à custa do mal que produz. Afinal, que valor poderia haver em tais escolhas livres se fossem ações aleatórias e, portanto, não determinadas pela natureza do agente?

Isso significaria que Mackie tem razão e que a existência do mal é logicamente incompatível com a existência de Deus? Meu objetivo agora é apresentar outra resposta ao problema lógico do mal baseado no livre-arbítrio que supere as objeções propostas por Mackie à defesa do livre-arbítrio.

\section{A DEFESA DO LIVRE-ARBÍTRIO DE ALVIN PLANTIGA}

A defesa do livre-arbítrio de Alvin Plantinga consiste em dar uma possível resposta a por que Deus permite o mal. Sua defesa visa a demonstrar que (1) e (2) 
são compatíveis entre si produzindo outra proposição que especifica a possível razão justificadora que é consistente com (1) e implica (2) em conjunção com (1). A verdade ou plausibilidade dessa outra proposição não é exigida; exige-se apenas sua possibilidade a fim de que se satisfaçam as condições requeridas de uma defesa.

Plantinga julga necessário começar esclarecendo o que entende por "liberdade" ou "livre-arbítrio". Ele escreve:

O que é relevante para a Defesa do Livre-Arbítrio é a ideia de ser livre com respeito a uma ação. Se uma pessoa é livre com respeito a uma dada ação, então tem a liberdade de realizá-la ou não; nenhuma das condições anteriores e/ou leis causais determinam que ela realizará ou não a ação. Ela tem o poder, no momento em questão, de realizar a ação, e tem o poder de não a realizar. A liberdade, concebida desse modo, não deve ser confundida com imprevisibilidade. Podemos conseguir prever o que faremos numa dada situação, ainda que tenhamos a liberdade, nessa situação, de fazer outra coisa. Se eu o conhecer bem, posso ser capaz de prever que ação realizará em resposta a certo conjunto de condições; daí não se segue que você não seja livre com respeito a tal ação. Por conseguinte, direi que uma ação é moralmente significativa para uma pessoa se for incorreto para ela a realização da ação, mas correto que evite realizá-la, ou vice-versa. (PLANTINGA, 1974b, p. 29-30, tradução nossa) ${ }^{6}$

Plantinga passa a expor sua defesa do livre-arbítrio. Ele diz que "um mundo contendo criaturas que são, de vez em quando, significantemente livres é mais valoroso, se todo o resto for igual, do que um mundo sem nenhuma criatura de fato livre" (PLANTINGA, 1974a, p. 116). Além disso, Deus não pode determinar que suas criaturas sempre façam o certo, porque desse modo elas não seriam realmente livres e tampouco fariam o correto livremente. Isso claramente depende de sua compreensão particular de incompatibilismo ${ }^{7}$, em que Deus não pode criar criaturas com livre-arbítrio e determinar como essas criaturas ajam, já que ser livre e agir livremente é simplesmente ser e agir sem ser determinado por eventos ou estados de coisas anteriores. Vale a pena enfatizar que seu argumento não depende da verdade do incompatibilismo, mas apenas de sua possibilidade lógica, para que seja verdadeiro. Note-se

\footnotetext{
6 "What is relevant to the Free Will Defense is the idea of being free with respect to an action. If a person is free with respect to a given action, then he is free to perform that action and free to refrain from performing it; no antecedent conditions and/or causal laws determine that he will perform the action, or that he won't. It is within his power, at the time in question, to take or perform the action and within his power to refrain from it. Freedom so conceived is not to be confused with unpredictability. You might be able to predict what you will do in a given situation even if you are free, in that situation, to do something else. If I know you well, I may be able to predict what action you will take in response to a certain set of conditions; it does not follow that you are not free with respect to that action. Secondly, I shall say that an action is morally significant, for a given person, if it would be wrong for him to perform the action but right to refrain or vice versa."

${ }^{7}$ Segundo a Enciclopédia de Filosofia de Stanford, o incompatibilismo é a visão de que agimos livremente somente se o determinismo for falso. A visão oposta ao incompatibilismo é chamada de compatibilismo, a qual assegura que o livre-arbítrio é compatível com o determinismo.
} 
que a possibilidade lógica é tudo de que precisamos para termos uma defesa, isto é, para argumentar que há compatibilidade lógica entre a existência de Deus e o mal no mundo.

Já que a origem do mal moral é o mau uso da liberdade por parte das criaturas, Plantinga segue afirmando que, se Deus eliminasse completamente a ocorrência do mal por meios deterministas ou retirando a liberdade das criaturas, então ele eliminaria a possibilidade do bem moral. Para que haja bem moral, é necessário haver liberdade para fazê-lo. "Portanto, para criar criaturas capazes de bem moral, Ele deve criar criaturas capazes de mal moral e não pode deixar essas criaturas livres para realizar o mal e, ao mesmo tempo, impedi-las de fazer tal coisa.” (PLANTINGA, 1974a, p. 167)

A proposição gerada, que é consistente com a onipotência, onisciência e bondade de Deus - ao mesmo tempo em que, em conjunção, implica que o mal existe -, é que "é possível que Deus não possa criar um universo contendo bem moral, mas sem mal moral" (PLANTINGA, 1974a, p. 167). De modo semelhante à defesa exposta por Mackie, é melhor um mundo com criaturas livres que tenham a possibilidade de fazer o mal do que criaturas totalmente determinadas que sempre façam o bem. Mas, novamente, mesmo sua formulação da defesa do livre-arbítrio está sujeita à objeção anterior de Mackie: por que Deus, sendo bom, onisciente e onipotente, não criou criaturas que, no exercício de sua liberdade, sempre livremente escolham o bem? Certamente isso estaria dentro de seu poder. Essa última afirmação é reforçada por G.W. Leibniz quando diz que Deus não apenas poderia criar qualquer mundo possível, mas, em virtude de sua bondade perfeita, quereria criar o melhor mundo possível antes do ato da criação. De acordo com Leibniz, o mundo atual é o melhor dos mundos possíveis, mas, para Mackie, se existe um mundo possível no qual criaturas com livre-arbítrio escolhem livremente apenas bons atos e Deus não instanciou esse mundo possível, então parece que não há um Deus onipotente, onisciente e sumamente bom.

Mais uma vez, parece que somos forçados a concluir pela inevitabilidade do problema lógico do mal. Na próxima seção, apresentarei a interpretação de Plantinga do problema proposto por Mackie e sua estratégia para superar a questão.

\subsection{A resposta de Plantinga à objeção de Mackie}


Plantinga (1974a, p. 169) prossegue respondendo à objeção específica de Mackie à sua defesa do livre-arbítrio a partir da seguinte questão: “quais mundos Deus poderia ter criado?”. Plantinga redefine a questão do ateólogo ${ }^{8}$ a partir de sua distinção entre criar e atualizar da seguinte maneira: "Se Deus é onipotente, então Deus poderia ter atualizado qualquer mundo possível[?]" (PLANTINGA, 1974a, p. 170). Ele também nota que há estados de coisas que Deus não poderia atualizar. Se Deus fosse contingente, ele não poderia atualizar mundos nos quais não inclui sua existência, tampouco poderia atualizar um mundo em que ele me faça abster livremente de realizar uma determinada ação, pois, se Deus assim o fizesse, então eu não agiria mais livremente.

Nesse sentido, Plantinga distingue dois tipos de atualização: uma forte e uma fraca. Deus pode atualizar fortemente apenas o que ele pode causar para ser atual. Então, dado que ele não pode, por uma questão de fato lógico, causar nossas decisões livres, Deus não pode atualizar fortemente qualquer uma de nossas decisões livres. ${ }^{9}$ A defesa do ateólogo não depende da possibilidade dessa atualização forte nas livres decisões das criaturas. Mas, se Deus sabe que uma pessoa executaria livremente uma ação se ele a colocasse em circunstâncias nas quais ela é significativamente livre com respeito àquela ação, e se Deus a faz estar nessa situação, então ele fracamente atualiza sua livre decisão. A hipótese de Mackie pode, então, ser reformulada como a afirmação de que Deus poderia ter atualizado um mundo possível que incluísse sua existência e a de seres significativamente livres, em que todos sempre fizessem apenas o que é certo nas circunstâncias previstas e atualizadas por ele.

De acordo com Plantinga, é possível que essa afirmação de Mackie seja falsa, pois é possível que toda pessoa sofra o que ele chama de depravação transmundial. Para Plantinga, toda pessoa que existe em qualquer mundo possível tem uma propriedade única que a distingue de todas as outras coisas possíveis. Essa propriedade é uma essência individuadora ou essência individual. Plantinga explica essa noção de essência da seguinte maneira: sendo X uma pessoa,

$[\ldots]$ a essência de $[\mathrm{X}]$ é uma propriedade que ele tem em todo mundo no qual existe e que não é exemplificada em qualquer mundo por qualquer outro objeto diferente de $[\mathrm{X}]$. Uma essência, simpliciter, é uma propriedade $\mathrm{P}$ tal que há um mundo $\mathrm{W}$ no qual há um objeto $\mathrm{X}$ que tem $\mathrm{P}$ essencialmente, e é

${ }^{8}$ Como dito, "ateólogo" é o termo que Plantinga usa para se referir aos antiteístas defensores do problema do mal.

${ }^{9}$ Estou assumindo a visão tradicional teísta de onipotência. Ao contrário do que Mackie diz em (4) acerca da onipotência, o que os teístas afirmam quando dizem que Deus é onipotente é que não há limites não lógicos ao que ele pode fazer. 
tal que em nenhum mundo $\mathrm{W}^{*}$ há um objeto que possua $\mathrm{P}$ e que seja diferente de X. (PLANTINGA, 1974a, p. 187, tradução nossa) ${ }^{10} 11$

Para uma determinada essência sofrer de depravação transmundial, ela tem de ser tal que, se Deus tivesse criado uma pessoa e lhe tivesse dado liberdade significativa, então, não importando as circunstâncias em que Deus a colocasse, ela erraria com respeito a pelo menos uma ação, desde que Deus a deixasse livre de maneira significativa. Consequentemente, se uma essência sofre de depravação transmundial, não está dentro do poder de Deus atualizar fracamente um mundo possível no qual a pessoa correspondente seja significativamente livre e ainda assim nunca tome uma decisão livre errada. Mas, se é possível que toda essência relevante sofra de depravação transmundial, então não importa o mundo com os seres significativamente livres que Deus fracamente atualize - haverá mal nesse mundo. Assim, Deus não poderia atualizar um mundo possível no qual nossas escolhas fossem livres e em que não houvesse mal moral. A defesa do livre-arbítrio conclui ser viável que Deus não possa atualizar um mundo em que haja algum bem moral e nenhum mal moral.

Podemos usar o seguinte exemplo para ilustrar a ideia: imagine uma mãe que tem três filhos briguentos. A mãe gostaria que eles se comportassem bem, mas não é isso que acontece. Independentemente do lugar da casa em que a mãe colocar os seus filhos, eles brigarão. Se os colocar na sala, haverá briga sobre qual desenho assistir; se os colocar na cozinha, haverá briga sobre quem ficará com o último biscoito do pote; se os colocar no quarto, brigarão acerca de qual jogo de videogame jogar. Mesmo que os garotos possuam a habilidade de se comportar, não importa onde a mãe os coloque, eles farão algo de errado. A proposta de Plantinga se assemelha à história da mãe com seus três filhos. É possível que cada pessoa que possa ser criada agisse erradamente em qualquer ambiente possível, como os três garotos.

Nos termos de Plantinga, aplicando-se a depravação transmundial (DTM) às essências individuadoras,

Uma essência E sofre de DTM se, e somente se, para todo mundo W tal que E implica a propriedade de ser significantemente livre em $\mathrm{W}$ e sempre fazer o que é correto em $\mathrm{W}$, há um estado de coisas T e uma ação A tal que (1) T é o maior estado de coisas que Deus atualiza fortemente em W,

\footnotetext{
${ }^{10}$ Plantinga desenvolve essa noção em detalhes no capítulo 5 de seu livro The nature of necessity (1974a).

11 " [...] an essence of Curley is a property he has in every world in which he exists and that is not exemplified in any world by any object distinct from Curley. An essence simpliciter is a property P such that there is a world W in which there exists an object $\mathrm{x}$ that has P essentially and is such that in no world $\mathrm{W}^{*}$ is there an object that has $\mathrm{P}$ and is distinct from $\mathrm{X} . "$
} 
(2) A é moralmente significativo para a instanciação de E em W e,

(3) se Deus tivesse atualizado fortemente $T$, a instanciação de $E$ teria errado com respeito a A. (PLANTINGA, 1974a, p. 188, tradução nossa) ${ }^{12}$

Com o DTM em mãos, Plantinga propõe a seguinte resposta: Deus criou um mundo contendo bem moral, mas não estava dentro de seu poder criar um mundo contendo bem moral sem criar um contendo mal moral, já que toda essência sofre de DTM.

De acordo com Plantinga, uma vez que $(\mathrm{R})$ especifica uma razão justificadora para Deus permitir o mal, e esta é compatível com (1), e (R) implica (2) em conjunção com (1), (1) e (2) são compatíveis. (R) serve para argumentar que também não estava ao alcance do poder de Deus criar um mundo contendo menos mal moral ou com muito mais bem moral que o nosso.

E quanto ao mal natural, o mal que se origina independentemente das ações humanas, como doenças, terremotos, tempestades, etc.? Plantinga formula sua defesa alegando que o mal natural é devido à livre atividade racional de seres não humanos, como Satanás e seus seguidores. Plantinga, novamente, não reivindica a verdade dessa hipótese, apenas sua possibilidade e consistência com (1). ${ }^{13}$

Essa é a versão de Plantinga da defesa do livre-arbítrio, cujo coração "é a tese de que é possível que Deus não tenha criado um universo contendo bem moral (ou tanto bem moral quanto este contém) sem ter criado um contendo mal moral” (PLANTINGA, 1974a, p. 167). Portanto, conclui Plantinga (1974a, p. 193), “a Defesa do Livre-Arbítrio rebate com sucesso as acusações de inconsistência levantadas contra o teísta. Se o mal é um problema para o

12 "An essence E suffers from transworld depravity if and only if for every world W such that E entails the properties is significantly free in $\mathrm{W}$ and always does what is right in $\mathrm{W}$, there is a state of affairs $\mathrm{T}$ and an action A such that

(1) $\mathrm{T}$ is the largest state of affairs God strongly actualizes in W,

(2) A is morally significant for E's instantiation in W, and

(3) if God had strongly actualized T, E's instantiation would have gone wrong with respect to A."

${ }^{13}$ Sobre a resposta de Plantinga ao mal natural, John Hick (2010, p. 369) a critica dizendo que "é inquietante descobrir que, para Plantinga, até mesmo a possibilidade lógica de que Deus existe parece depender da existência do diabo". Hick erra o alvo ao supor que Plantinga visa uma teodiceia; por mais mitológico que possa parecer, Plantinga não assume sua verdade, apenas sua possibilidade lógica. James F. Harris (2002) propõe uma alternativa mais razoável para explicar o mal natural, dada a defesa do livre-arbítrio de Plantinga. Ele se baseia na ênfase que Harry Frankfurt dá ao analisar o cuidado humano: como seres humanos, livremente escolhemos cuidar de certos tipos de coisas e dar mais atenção às coisas mais importante para nós. O que é notável é que as coisas pelas quais nos importamos cuidadosamente são coisas que são, escreve Harris (2002, p. 249), "caracterizadas por risco e incerteza que tornam a pessoa vulnerável a desapontamento ou perda se o objeto com o qual a pessoa se importa for perdido ou danificado de alguma forma”. Dessa maneira, pessoas ou objetos precisam estar vulneráveis a danos, doenças ou morte para que cuidemos deles, já que cuidar deles envolve investir tempo, energia e recursos para promover ou proteger seu bem-estar. Seria difícil ver onde nosso cuidado estaria se não houvesse males possíveis que chegassem àquilo com que nos importamos. 
crente, ele não o é no sentido de que a existência do mal - moral ou natural - é inconsistente com a existência de Deus".

\title{
3.2 Repercussões e críticas da resposta de Plantinga
}

Desde a resposta de Plantinga, diversos filósofos notaram positivamente o sucesso de sua defesa face ao problema lógico do mal. De acordo com William Alston (1991, p. 49), "Plantinga [...] estabeleceu a possibilidade de Deus não poder atualizar um mundo contendo criaturas livres que sempre fazem a coisa certa". William Rowe concorda:

\begin{abstract}
Alguns filósofos argumentaram que a existência do mal é logicamente inconsistente com a existência do deus teísta. Ninguém, penso eu, conseguiu estabelecer uma afirmação tão extravagante. De fato, concedido o incompatibilismo, há um argumento bastante convincente para a visão de que a existência do mal é logicamente consistente com a existência do deus teísta. (ROEW, 1979, p. 335, nota 1, tradução nossa) ${ }^{14}$
\end{abstract}

Mas será que Plantinga foi realmente vitorioso em sua defesa? Vejamos algumas críticas. Swinburne (1998), contra Plantinga, aponta que a hipótese de uma depravação transmundial é altamente implausível. Deus, diante de uma vasta infinitude de possibilidades de agentes livres, em infinitas circunstâncias diferentes, dificilmente não encontraria alguns agentes que em algumas circunstâncias não fariam somente o bem. De qualquer forma, Deus poderia dar-lhes liberdade somente nos momentos em que prevê os agentes escolhendo livremente o que é certo, de maneira que tirasse a liberdade das criaturas quando previsse que elas fariam algo de errado. Assim, o bem moral seria preservado e o mal moral, eliminado. Além disso, a possibilidade do mal moral não seria necessária se Deus quisesse dar às criaturas o livre-arbítrio libertário juntamente à possibilidade de fazerem o bem moral.

Steven Boer (1978) nota que as várias tentativas de pessoas más de agirem maldosamente neste mundo falham por várias razões, como falta de bom planejamento, imprevistos, sorte ou coisas semelhantes. Desse modo, podemos imaginar um mundo possível em que todas as tentativas de agir maldosamente sejam malsucedidas, caso Deus atualize fortemente determinada situação que impeça o agente de agir maldosamente e provocar dor

\footnotetext{
14 "Some philosophers have contended that the existence of evil is logically inconsistent with the existence of the theistic God. No one, I think, has succeeded in establishing such an extravagant claim. Indeed, granted incompatibilism, there is a fairly compelling argument for the view that the existence of evil is logically consistent with the existence of the theistic God."
} 
ou sofrimento. $\mathrm{O}$ agente ainda assim agiria livremente, mas se frustraria por não conseguir fazer o mal e provocar dor ou sofrimento.

De forma semelhante, David Lewis (1993) diz que, mesmo que tenhamos livre-arbítrio libertário, Deus ainda poderia ter agido de modo a evitar as consequências de nossas decisões. Deus poderia ter evitado, por exemplo, o genocídio nazista caso os líderes importantes morressem de doenças antes de poderem agir maldosamente, ou atualizar as circunstâncias de maneira diferente de modo que eles falhassem em promover o mal, ou até mesmo por uma manifestação miraculosa impedisse a realização do mal.

Talvez a crítica mais persuasiva à hipótese da depravação transmundial proceda de Richard Otte (2009). Seu argumento contra a possibilidade de que toda essência sofra de depravação transmundial consiste em descrever um mundo possível que implica que não é possível que todas as essências sofram de depravação transmundial. Sua descrição é a seguinte: imagine um mundo possível M1 em que só existe Adão e há apenas uma escolha livre que ele pode fazer, sendo tal escolha a de se matar ou não se matar, e assumindo-se que o suicídio é um ato moralmente condenável. Em M1, Adão faz a escolha certa ao não se matar e, portanto, escolhe somente o bem. Nesse mundo possível, Deus atualiza fortemente uma situação na qual Adão se encontra para exercer sua liberdade. Adão escolhe não se matar e, por essa razão, Deus fala a Adão que ele escolheu o certo e como recompensa irá torná-lo governante do Éden. Segundo Otte, se Adão tem essa escolha livre em M1, então existe outro mundo possível M2 em que Adão decide se matar. O estado total de coisas que Deus atualiza fortemente após a escolha livre e correta de Adão é diferente do estado total de coisas que Deus poderia atualizar se Adão escolhesse se matar. Se fosse o caso Adão decidir se matar, Deus não poderia anunciar a Adão que ele fez o certo, e tampouco nomeá-lo como governante do Éden; tais ações de Deus são inconsistentes com a morte de Adão.

Nas definições de Plantinga, para uma determinada essência sofrer de depravação transmundial ela tem de ser tal que, se Deus tivesse criado a pessoa e tivesse dado a ela liberdade significativa, então não importariam as circunstâncias em que Deus a colocasse, ela erraria com respeito a pelo menos uma ação, desde que Deus a deixasse livre de maneira significativa. Assim, se Adão sofresse de depravação transmundial e Deus atualizasse fortemente o estado total de coisas de M1 (doravante TM1), então Adão teria feito a escolha errada em se matar. Obviamente, isso não é possível, pois, se Deus atualizasse fortemente TM1, Adão não se mataria, já que TM1 e Adão se matar não podem coexistir. Não é possível a Deus atualizar fracamente a decisão de Adão de se matar ao mesmo 
tempo em que atualiza fortemente TM1, pois, se TM1 ocorre, é impossível que Adão se mate, uma vez que TM1 inclui a fala de Deus para Adão de que ele fez o certo, bem como sua nomeação para governante do Éden, o que implica que Adão escolheu o certo. Porém, se uma pessoa escolhe apenas o bem em algum mundo, então ela não sofre de depravação transmundial; portanto, conclui Otte, não é possível que Adão sofra de depravação transmundial, já que, necessariamente, se Deus atualiza fortemente TM1, Adão não se mata. Como Adão tem apenas uma escolha livre, se TM1 é atual, temos um mundo no qual existe o bem moral, mas não o mal moral. ${ }^{15}$

Dadas todas estas críticas, parece que voltamos à posição inicial de não ter uma resposta satisfatória ao problema lógico do mal. A seguir, apresentarei uma resposta mais econômica que neutraliza o argumento de Mackie.

\section{RESPOSTA MAIS ECONÔMICA}

Há uma estratégia menos comprometedora que anula o argumento lógico do mal com eficácia. Considere as duas primeiras premissas de Mackie:

(1) Deus é onipotente, onisciente e sumamente bom;

(2) O mal existe.

Mackie reconhece que a contradição não surge imediatamente das premissas (1) e (2), já que, para que haja um conjunto de proposições contraditórias, é necessário que um dos membros seja a rejeição ou negação de outro membro. Desse modo, ele define os termos utilizados para concluir que (5) uma coisa boa, onisciente e onipotente elimina completamente o mal. Porém, como vários filósofos da religião concordaram, é exigido que (5) seja uma verdade necessária para ser demonstrada a incompatibilidade lógica entre (1) e (2). Uma proposição é necessariamente verdadeira se for impossível que seja falsa, ou se sua negação não for possivelmente verdadeira. William Rowe (2007) propõe a seguinte ilustração para se compreender esse ponto. Considere essas duas proposições:

(1B) O objeto na minha mão direita é uma moeda;

(2B) O objeto na minha mão direita não é cinco centavos.

Obviamente, (1B) e (2B) não são logicamente inconsistentes, pois ambos podem ser

\footnotetext{
${ }^{15}$ Para ser honesto, Otte (2009) no mesmo artigo oferece uma nova definição que contorna a objeção que el levanta, mas não tratarei disso aqui por questão de espaço e objetivo.
} 
verdadeiros. Não há nada logicamente contraditório na ideia de que a moeda na minha mão direita possa ser de 25 ou 50 centavos. Porém, podemos adicionar a seguinte afirmação:

(3B) Toda moeda na minha mão direita é uma moeda de cinco centavos.

A partir de (1B) e (3B), podemos derivar:

(4B) O objeto em minha mão direita é uma moeda de cinco centavos;

(4B) em conjunção com (2B) é uma explicita contradição. Não obstante, mesmo que (4B) seja verdade, não estabeleceríamos que as duas afirmações originais, nomeadamente (1B) e (2B), são logicamente inconsistentes por si só. Embora o grupo inteiro, o par original e as duas declarações adicionais em conjunto, sejam explicitamente contraditórias, não conseguimos mostrar que o par original é logicamente contraditório por si só. A razão disso é que, embora (3B) possa ser verdadeira, ela não é necessariamente verdadeira. Eu poderia simplesmente ter uma moeda de 25 ou 50 centavos na minha mão direita. Uma vez que (3B) poderia ter sido falsa, ela não é uma verdade necessária, e, se (3B) não é uma verdade necessária, então (1B) e (2B) não são logicamente inconsistentes por si sós. Assim, nas palavras de Rowe (2007, p. 115), "para estabelecer duas afirmações como logicamente inconsistentes, adicionando uma afirmação e, em seguida, derivando afirmações explicitamente contraditórias, a afirmação adicional deve ser não apenas verdadeira, mas necessariamente verdadeira".

Aplicando esse raciocínio ao argumento de Mackie, podemos perguntar se a cláusula adicionada, nesse caso (5), é uma verdade necessária. Mas será que (5) é de fato uma verdade necessária de modo a estabelecer uma inconsistência lógica de (1) em conjunção com (2)? Por que pensar que uma coisa boa, onisciente e onipotente não permitiria o mal? Em nossa discussão acerca da defesa do livre-arbítrio, afirmamos que a liberdade das criaturas é a razão pela qual o mal existe; porém, não precisamos nos comprometer com a possibilidade do livrearbítrio para eliminar a suposta inconsistência, uma vez que é difícil estabelecer que (5) é de fato uma verdade necessária. Sobre isso, Rowe escreve:

Em nossa própria experiência sabemos que o mal às vezes está conectado com o bem de tal maneira que somos impotentes para alcançar o bem sem permitir o mal. Além disso, em tais casos, o bem às vezes supera o mal, de modo que um ser bom intencionalmente permite que o mal ocorra a fim de realizar o bem que o supera. (ROWE, 2007, p. 116, tradução nossa) ${ }^{16}$

\footnotetext{
16 "For in our own experience we know that evil is sometimes connected with good in such a way that we are powerless to achieve the good without permitting the evil. Moreover, in such instances, the good sometimes outweighs the evil, so that a good being might intentionally permit the evil to occur in order to realize the good which outweighs it."
} 
É possível que Deus permita o mal tendo em vista um bem maior que não pode ser alcançado se não houver mal. Perceba que não estamos assumindo que Deus permite o mal com o objetivo de realizar algum bem; apenas a possibilidade é suficiente a fim de se rejeitar (5) como uma verdade necessária, que é condição exigida para (1) e (2) serem logicamente inconsistentes por si mesmas. Mackie tem a difícil tarefa de provar que (5) é uma verdade necessária.

Note-se que de acordo com (4) não há limites ao que uma coisa onipotente pode fazer. Deus poderia sempre alcançar o bem e evitar o mal. Contudo, (4) ignora a maneira como tradicionalmente os teístas têm entendido a onipotência de Deus. Onipotência não é o poder de fazer o que é logicamente impossível, como um círculo quadrado; o que os teístas afirmam quando dizem que Deus é onipotente é que não há limites não lógicos ao que ele pode fazer. E, como observamos em nossa experiência ordinária, há bens que só são atingidos com a ocorrência de males. É possível, diria Rowe, que "a ocorrência de alguns males em nosso mundo seja logicamente necessária para a obtenção de bens que os superam, de modo que a tarefa de produzir esses bens sem permitir os males que estão ligados a eles é tarefa tão impossível quanto fazer um quadrado redondo" (ROWE, 2007, p. 117). Logo, uma vez que uma proposição não é necessariamente verdadeira se sua negação não for possivelmente verdadeira, e é possível que um ser sumamente bom, onisciente e onipotente não possa impedir a ocorrência de um mal sem perder um bem maior, então não é uma verdade necessária a afirmação de que um ser sumamente bom, onisciente e onipotente eliminaria completamente o mal.

Portanto, temos uma resposta econômica que neutraliza o argumento de Mackie, pois, com nossa discussão, podemos concluir que os males que existem em nosso mundo podem ser logicamente necessários para a ocorrência dos bens que os superam, de maneira que a inconsistência lógica entre (1) e (2) não foi estabelecida por (5). Não provamos que a tese do ateólogo é impossível mostrando a possível boa razão pela qual Deus permite o mal, como a defesa do livre-arbítrio intencionou, mas observamos que não se estabeleceu que (1) e (2) tomados em conjunto sejam logicamente inconsistentes. Até que alguém produza uma afirmação necessariamente verdadeira que em conjunção com (1) e (2) revele inconsistência ou contradição, estamos justificados em concluir que o problema lógico do mal não é um problema para o teísmo. 


\section{CONSIDERAÇÕES FINAIS}

Neste artigo, discuti o problema lógico do mal conforme formulado por Mackie. Inicialmente apresentei sua proposta e duas possíveis respostas discutidas pelo próprio Mackie. Em seguida, expus a defesa do livre-arbítrio de Plantinga, que visa a superar os desafios sugeridos por Mackie. Concluí que a defesa do livre-arbítrio possui críticas que o desestabilizam. Por fim, apresentei uma resposta mais econômica que neutraliza o argumento de Mackie e constatei que o mal não é um problema lógico para o teísmo. Concluo, portanto, que o mal não fornece um problema lógico à existência de Deus. 


\section{REFERÊNCIAS}

ALSTON, W. The inductive argument from evil and the human cognitive condition. Philosophical perspectives 6, 1991, p. 29-67.

BOER, Steven. Is the free will defense irrelevant? Analysis 38, 1978, p. 110-112.

HARRIS, James F. Analytic philosophy of religion. USA: Virginia, 2002.

HICK, John H. Evil and the god of love. 5th edition. London: Macmillan, 2010.

HICKSON, Michael W. A brief history of problems of evil. In: J.P. McBrayer and D. Howard-Snyder (ed.). The Blackwell companion to the problem of evil, 2013, p. 3-18.

LEWIS, David. Evil for freedom's sake. Philosophical papers 22, 1993, p. 149-172.

MACKIE, J. L. Evil and omnipotence. Mind, 64, 1955, p. 200-212.

OTTE, R. Transworld, depravity and unobtainable worlds. Philosophy and phenomenological research 78, 2009, p. 165-177.

PLANTINGA, A. God, freedom and evil. Michigan: Harper and Row, 1974. . The nature of necessity. Oxford: Clarendon Press, 1974.

ROWE, William L. Philosophy of religion: an introduction. 5th edition. Belmont, CA: Wadsworth/Cengage Learning, 2007.

. The problem of evil and some varieties of atheism. American philosophical quarterly 16, 1979, p. 335-341.

SWINBURNE, Richard. Providence and the problem of evil. Oxford: Clarendon Press, 1998. 